\title{
Антитеррористическая функция государства и поиск баланса
}

\author{
Миц Д.С. \\ Парламентская Ассамблея Организации Договора о коллективной безопасности (ОДКБ), \\ Россия, Санкт-Петербург, ул. Шпалерная, 47, 191015 \\ E-mail: a-83@bk.ru \\ ORCID ID: 0000-0002-6238-8501
}

\begin{abstract}
Аннотация. Рассмотрена антитеррористическая функция государства, которая развивается за счет обеспечения ее эффективной антитеррористической политикой с целью поиска баланса личности, общества и государства в условиях террористической активности. Анализ категории «антитеррористическая функция государства» осуществляется в совокупности диалектического и системного методов исследования, а также путем концептуального подхода в отношении искомого баланса. В ходе анализа сформулирована и научно обоснована авторская позиция возложенный на национальную политику замысел противодействия современному терроризму выделяет антитеррористическую функцию государства в качестве полноценного средства реагирования в системе обеспечения национальной безопасности. В работе отражена актуальная особенность рассматриваемой функции - социальные системы суть профилактических мероприятий антитеррористической функции государства. Заблаговременно социальные системы антитеррористической функции государства позволяют нейтрализовать актуальные угрозообразующие факторы.
\end{abstract}

Ключевые слова: терроризм, безопасность, реагирование; обеспечение.

Для цитирования: Миц Д.С. 2020. Антитеррористическая функция государства и поиск баланса. NOMOTHETIKA: Философия. Социология. Право. 45 (2): 323-329. DOI 10.18413/2712-746X-202044-2-323-329

\section{The anti-terrorist function of the state, and finding balance}

\author{
Denis S. Mits \\ Parliamentary Assembly of the Collective Security Treaty Organization, \\ 47 Shpalernaya street, 191015, St. Petersburg, Russia \\ E-mail: a-83@bk.ru \\ ORCID ID: 0000-0002-6238-8501
}

\begin{abstract}
The article considers the anti-terrorist function of the state, which develops at the expense of ensuring its effective anti-terrorist policy. The aim of the article is to find the balance of the individual, society and state in the conditions of terrorist activity. The analysis of the category "anti-terrorist function of the state" is carried out in the aggregate of dialectical and systemic methods of research, as well as through a conceptual approach to the desired balance. In the course of the analysis the article formulates and scientifically substantiates the author's position - the idea of combating modern terrorism assigned to the national policy allocates the anti-terrorist function of the state as a full-fledged means of response in the system of ensuring national security. The article reflects the actual feature of the considered function social systems the essence of preventive measures of the antiterrorist function of the state. In advance of the social system of anti-terrorist functions of the state allow you to neutralize the actual protopurusha factors.
\end{abstract}

Keywords: terrorism; security; response; security.

For citation: Mits D.S. 2020. The anti-terrorist function of the state, and finding balance. NOMOTHETIKA: Philosophy. Sociology. Law series. 45 (2): 323-329 (in Russian). DOI 10.18413/2712-746X-2020-44-2-323-329 


\section{Введение}

Для процессов глобализации характерна определенная двойственность направлений:

1) интернационализация внутреннего регулирования;

2) конституционализация международных отношений.

В свете геополитических изменений международная общественность имеет представление об отсутствии эффективного консолидированного международного антитеррористического сотрудничества.

При этом правовое обеспечение антитеррористической функции государства зависит от устойчивых каналов правового взаимодействия внутреннего и внешнего уровня. В странах с демократическим режимом единственным источником государственной власти признается народ. Однако в обществе сложилась обывательская позиция, что политику, в том числе антитеррористическую, формирует специальный круг представителей власти без учета мнения населения [Кубякин, Плотников, 2015].

Факторы, ослабляющие законность, также воздействуют на динамику воспроизводства деструктивных, в том числе террористических, проявлений. Профилактика терроризма и активная деятельность по локализации вредоносных последствий от радикализма, вражды и ненависти, экстремизма и терроризма в полном объеме возможна с использованием потенциала институтов гражданского общества. В тоже время информационнопропагандистские мероприятия через возможности СМИ в рамках антитеррористической деятельности требуют существенной оптимизации в условиях соблюдения законности.

Конституционный принцип народовластия позволяет на общем уровне использовать законодательно обеспеченные каналы взаимодействия (с учетом взаимной ответственности) между гражданином и государством, в том числе при противодействии терроризму [Цыбулевская, Милушева, 2007]. Однако во многом это общие сложные тенденции национальной безопасности:

1) неурегулированные вопросы международного сотрудничества;

2) неурегулированные вопросы координации государственного уровня.

Терроризм как угроза национальной безопасности встраивается в систему методологического обеспечения его противодействия. При этом терроризм усиленно трансформируется в отличие от других угроз национальной безопасности.

В общей методологии национальной безопасности принцип баланса сил противодействия всем угрозам на едином уровне чреват ростом террористической активности и снижением эффективности антитеррористической функции государства. Важно формировать антитеррористическую функцию государства автономно от всей системы обеспечения национальной безопасности. Антитеррористическая политика должна всецело отражать антитеррористическую функцию государства с учетом современных тенденций. При этом категория «уголовная ответственность» является средством осуществления стабильной антитеррористической политики в целях создания условий для нормальной жизнедеятельности социума [Дворецкий, 2018]. Кроме того, с помощью гражданского общества отражение антитеррористической функции государства в соответствующей политике возможно при полноценной роли и значении институтов гражданского общества как антитеррористических субъектов.

Представляется, что если угроза безопасности и опасности существует для личности, общества и государства, то для эффективного развития антитеррористической функции государства лишь государственных сил будет недостаточно.

Проблематика антитеррористической функции государства не обозначает вопроса о значении гражданского общества как базового, а напротив игнорируется в ходе учета в антитеррористическом механизме или воспринимается в случае обеспечения анонимного или персонифицированного сотрудничества.

Правовые вопросы гражданского общества находятся в незавершенном состоянии, в этой связи прогнозируются дополнительные сложности в ходе профилактики терроризма. 
Развитие гражданского общества в системе антитеррористической функции государства зависит от учета исторического и социального контекста; от накопленного мирового опыта и национальной специфики [Цыбулевская, 2014].

Располагая широкими политико-правовыми возможностями, антитеррористическая функция государства, формирует искомый эффективный комплекс. При этом отсутствие полноценного антитеррористического сознания в социуме не позволяет рассчитывать на возможные политико-правовые позиции государственного реагирования.

Антитеррористическая деятельность государственных структур при сотрудничестве институтов гражданского общества - эффективная схема. Обратный вектор этой схемы имеет отрицательную составляющую, которая способствует свертыванию оптимальных процессов. Однако использование в рамках антитеррористической функции государства возможностей интернета и СМИ определяет прямые антитеррористические действия институтов гражданского общества, воздействуя непосредственно на террористическое сознание для его оздоровления.

Институты гражданского общества связаны с независимыми СМИ [Кубякин, 2015]. Их функция способствует адекватному отражению в обществе перемен, критическом анализе социально-политической и общественно-экономической ситуации в стране, а также осуществлению контроля в области государственной власти и защите интересов граждан, в том числе от террористических угроз [Цыбулевская, Милушева, 2008].

Сосуществование антитеррористической функции государства в физическом и информационном пространстве накладывает на формирование и реализацию антитеррористических мероприятий соответствующие специфические закономерности. Данные обстоятельства следует учитывать на этапах совершенствования организационного и правового обеспечения рассматриваемой сферы. Отражение значения возможностей СМИ в практике реализации системы антитеррористической функции государства оправдано требует эффективного и реального сотрудничества данных средств и государственных антитеррористических сил [Кубякин, Плотников, 2016].

Участие СМИ в системе антитеррористической функции государства всецело возможно в форме профилактики терроризма. При этом в ходе реализации данной формы существует наибольшее опасение нарушения законности, в том числе конституционной, как политико-правового режима в государстве. Без полноценно разработанного политикоправового подхода реализовать данный вопрос представляется затруднительным в современных юридических условиях [Кубякин, Плотников, 2016]. Нарушение законности связано с низкой юридической техникой, отсутствием соответствия ведомственного нормотворчества вышестоящим по юридической силе нормативным правовым актам, потребностью в подготовке специалистов в области правотворчества. Происходит подмена (особенно в рамках правового обеспечения антитеррористической деятельности) компетентности «жизненным опытом» (он не может заменить профессионализм) [Липинский, 2018].

При преодолении воздействия негативных факторов в области законности целесообразно осуществление следующего комплекса мероприятий:

1) мониторинг среды воспроизводства указанных проявлений;

2) прогнозирование возможностей для данного воспроизводства;

3) выявление, предупреждение и пресечение воспроизводства.

Законность как политико-правовой режим связан с унифицированным демократическим режимом. Антитеррористическая функция государства в условиях данных политикоправовых режимов развивается относительно преодоления недостатков указанных режимов. Механизмы антитеррористической деятельности эволюционируют с учетом противоречий политико-правовых систем [Кубякин, Плотников, 2015]. При этом профилактика терроризма во многом связана с эффективным укреплением законности в общем комплексе.

Основой гражданского общества является демократический плюрализм и проявления культурных различий. При этом в современных условиях данное общество подверже- 
но радикализации, что при определенных (в том числе при провокации) условиях трансформируется в экстремистскую деятельность [Сморгунова, 2019].

Мнение народа по вопросам дальнейшего развития антитеррористической функции государства является ключевым средством наибольшей оптимизации указанного процесca. Мировая практика считает оптимальным комплекс наступательных антитеррористических мероприятий, применяемых в режиме демократического правового государства. В этой связи организационно-правовые проблемы данного режима по объективным причинам более сложны для их решения и непосредственно воздействуют на эффективность антитеррористической функции государства [Кубякин, Горбенко, 2014]. Конституционно закрепленные идеологическое и политическое многообразие при запрете государственной идеологии активизируют негативные факторы воспроизводства деструктивных, в том числе террористических, проявлений.

В современных условиях антитеррористическая функция государства зависит от межгосударственной борьбы за сферы влияния; от «санкционного» давления; от укрепления национальной экономической безопасности. По причине изменения геополитической карты мира международные антитеррористические лидеры под влиянием разных процессов осуществляют поиск новых форматов взаимодействия. Под влиянием процессов глобализации выделены новые требования к антитеррористической функции государства как к элементу международной и национальной безопасности.

Современное мировое конкурентоспособное общество характеризуется процессом информатизации [Ветютнев 2018]. Социально-экономическая и геополитическая обстановка динамично изменяется, их последствия все сложнее поддаются прогнозам в сфере обеспечения полноценной безопасности [Буткевич, 2018], в том числе в сфере противодействия террористическим проявлениям.

Следует отметить, что безопасность личности, общества и государства является предметом рассмотрения науки, политики, футурологов, фантастов под влиянием достижения математики, информатики, кибернетики и результатов новых информационных технологий. Философы, политологи, политики, юристы, социологи и специалисты технических, естественных и гуманитарных наук озабочены изменениями геополитики научноисследовательских систем антитеррористической функции государства, а также идентификации в этой системе человека [Бачило, Шмаков, 2017].

Процессы глобализации и информатизации на планетарном уровне воспроизводят проявления вражды и ненависти, экстремизма и терроризма. Данное обстоятельство требует усиления внимания политических, правовых наук и структур, мобилизации всех ресурсов устойчивого гуманитарного развития и интересов планеты в современных условиях существования социума. При этом толерантность - важный индикатор социальной, нравственной, организационной зрелости социума планеты, а также индикатор искомого баланса [Бачило, 2013].

Международное правовое обеспечение неразрывно от экономических и политических отношений [Ишеков, 2017]. Современный этап глобализации характеризуется как усиление потребности мирового сообщества в объективной, достоверной и своевременной информации об общественно-политических процессах. Данную особенность используют террористические структуры для проведения полноценных комплексных информационнопсихологических акций, что требует адекватного государственного антитеррористического реагирования.

Международные споры, разрешение которых осуществляется в современных условиях за счет военно-политических механизмов, способствуют циркуляции воспроизводства международных террористических проявлений [Кириленко, Алексеев 2018]. Традиционно отдельным блоком стран поддерживаются политические провокации в целях последующего применения международных принудительных действий с использованием преданных им вооруженных сил и вооружений для контроля над территориями, в том числе суверенных государств. В этой связи по-прежнему актуальным является использо- 
вание дипломатических и парламентских возможностей для оптимизации согласованных антитеррористических позиций.

Для международной безопасности важным является недопустимость нарушения или злоупотребления правом по обстоятельствам соблюдения принципа добросовестности. Внешнеполитический курс Российского государства характеризуется последовательностью такой цели, что способствует поддержанию режима верховенства права в системе современных международных правоотношений [Богатырев, Каламкарян, 2018].

\section{Заключение}

На трансформацию международного политико-правового обеспечения борьбы с международным терроризмом воздействуют следующие процессы глобализации: 1) экономический; 2) политический; 3) правовой.

Страны в режиме антитеррористической функции государства отстаивают свои геополитические интересы, установленные посредством политико-правового обеспечения.

Антитеррористическая функция государства при своей реализации зависит от соответствующего правового обеспечения в контексте адекватного государственного реагирования и международной безопасности [Киречёк, 2016]. При этом антитеррористическая политика зависит от антитеррористического сознания. В частности, СМИ в системе антитеррористической функции государства позволяют склонить на сторону мирного существования и диалога потенциальных пособников террористов.

В условиях соблюдения законности развитие гражданского общества и оптимизация антитеррористической функции государства - зависимые друг от друга политикоправовые тенденции. В этой связи при демократическом режиме действия и бездействия государственных и иных структур по реализации антитеррористической функции государства помещены под внимательный контроль со стороны заинтересованных структур, законодательной и судебной власти, а также общественного мнения.

Представляется, что устойчивое развитие оптимизации национальной безопасности способствует обеспечению законности и позволит улучшить профилактическую антитеррористическую функцию государства.

\section{Список литературы}

1. Бачило И.Л. 2013. О причинах и мотивах правонарушений в области расовых, этнических, национальных, религиозных отношений. Государство и право. 3: 33-42.

2. Бачило И.Л., Шмаков М.А. 2017. О трансформации институтов «государство» и «право» в информационном обществе. Государство и право, 11: 81-88.

3. Богатырев В.В., Каламкарян Р.А. 2018. Международно-правовая включенность Российской Федерации в международный договорный процесс как фактор обеспечения юридической безопасности государств. Вестник Московского университета МВД России, 3: 159-162.

4. Буткевич С.А. 2018. Семья как институт предупреждения экстремизма и терроризма (правовые и социальные аспекты). Вестник Уральского юридического института МВД России, 1: 42-47.

5. Ветютнев Ю.Ю. 2018. Проблемы и перспективы информационного общества: теоретико-правовой взгляд. Аграрное и земельное право, 7 (163): 4-8.

6. Дворецкий М.Ю. 2018. Уголовная ответственность: проблемы теории и правоприменительной практики. В кн.: Уголовная политика и правоприменительная практика: сборник материалов V Международной научно-практической конференции. Санкт-Петербург. ИД «Петрополис», $444 \mathrm{c.}$

7. Ишеков К.А. 2017. Модернизационные процессы в контексте человеческого измерения. Вестник Института законодательства Республики Казахстан, 2(47): 34-39.

8. Киречёк Е.В. 2016. Национальная безопасность, национальные интересы и стратегические национальные приоритеты Российской Федерации в контексте обеспечения прав человека. Пенитенциарное право: юридическая теория и правоприменительная практика, 4 (10): 85-89.

9. Кириленко В.П., Алексеев Г.В. 2018. Противодействие идеологии современного терроризма. Управленческое консультирование, 5(113): 8-18. 
10. Кубякин Е.О., Горбенко А.И. 2014. Противодействие террористическим угрозам на федеральном и муниципальном уровнях трансформирующегося российского общества: социологический анализ. Вестник Московского государственного гуманитарно-экономического института, 3 (19): 16-19.

11. Кубякин Е.О., Плотников В.В. 2015. Социологическое исследование предпосылок возникновения экстремизма. Экстремизм и его негативное влияние на уровень национальной безопасности России: криминологический и экономический аспекты. Материалы II Всероссийской научно-практической конференции. Краснодарский университет МВД России. 198 с.

12. Кубякин Е.О., Плотников В.В. 2015. Феномен социального сознания как интенциональный ориентир исследования проблемы экстремизма. Общество и право, 4 (54): 289-293.

13. Кубякин Е.О., Плотников В.В. 2016. Противодействие социальной деструктивности в условиях глобальной трансформации общества: управленческий аспект. Человек. Общество. Инклюзия. № 2-1(26): 35-40.

14. Кубякин Е.О., Плотников В.В. 2016. Социокультурная детерминированность индивидуальной деятельности. Анализ факторов социальных противоречий. Философия права, 1 (74): 55-58.

15. Кубякин Е.О., Карнаушенко Л.В., Куликов Е.М., Городенцев Г.А. 2015. Экстремизм в условиях прогресса информационно-компьютерных технологий. Краснодар. Краснодарский университет МВД России. 102 с.

16. Липинский Д.А. 2018. О специалисте в сфере правотворчества. Юридическая наука и практика: Вестник Нижегородской академии МВД России. Нижний Новгород, 2 (42): 455-457.

17. Сморгунова В.Ю., Калинин Е.Ю. 2019. Эволюция идеи правосудия в России: от поиска справедливости к каре и обратно. Юридическая наука: история и современность, 1: 186-192.

18. Цыбулевская О.И. 2014. Государство и гражданское общество: методологический аспект взаимодействия. В кн.: Ответственность власти перед гражданским обществом: механизмы контроля и взаимодействия: сборник трудов конференции. Саратов. Поволжский институт управления им. П.А. Столыпина. 272 с.

19. Цыбулевская О.И., Милушева Т.В. 2007. Нравственно-правовая культура субъектов власти и некоторые вопросы правоприменения по усмотрению. Ленинградский юридический журнал, 4 (10): 18-38.

20. Цыбулевская О.И., Милушева Т.В. 2008. Общественный контроль как фактор ограничения власти. Право и управление. XXI век, 3 (8): 28-33.

\section{References}

1. Bachilo I.L. 2013. O prichinakh i motivakh pravonarushenii v oblasti rasovykh, etnicheskikh, natsional'nykh, religioznykh otnoshenii [About the reasons and motives of offenses in the field of racial, ethnic, national, religious relations]. State and law, 3: 33-42. (In Russ.).

2. Bachilo I.L., Shmakov M.A. 2017. O transformatsii institutov «gosudarstvo» i «pravo» v informatsionnom obshchestve [On the transformation of the institutions "state" and "law"in the information society]. State and law, 11: 81-88. (In Russ.).

3. Bogatyrev V.V., Kalamkaryan R.A. 2018. Mezhdunarodno-pravovaya vklyuchennost' Rossiiskoi Federatsii v mezhdunarodnyi dogovornyi protsess kak faktor obespecheniya yuridicheskoi bezopasnosti gosudarstv [International legal involvement of the Russian Federation in the international Treaty process as a factor of ensuring the legal security of States]. Bulletin of the Moscow University of the Ministry of internal Affairs of Russia, 3: 159-162. (In Russ.).

4. Butkevich S.A. 2018. Sem'ya kak institut preduprezhdeniya ekstremizma i terrorizma (pravovye i social'nye aspekty) [Family as an Institute for preventing extremism and terrorism (legal and social aspects)]. Bulletin of the Ural law Institute of the Ministry of internal Affairs of Russia, 1: 42-47.

5. Vetyutnev Y.Y. 2018. Problems and prospects of information society: theoretical and legal view. Agrarian and land law, 7 (163): 4-8.

6. Dvoretskii M.Y. 2018. Ugolovnaya otvetstvennost': problemy teorii i pravoprimenitel'noi praktiki [Criminal liability: problems of theory and law enforcement practice]. In: Criminal policy and law enforcement practice: collection of materials of the $\mathrm{V}$ International scientific and practical conference Ed. by E.N. Rakhmanov. Saint-Petersburg. ID "Petropolis". 444 p. (In Russ.).

7. Ishekov K.A. 2017. Modernizacionnye processy v kontekste chelovecheskogo izmereniya [Modernization processes in the context of the human dimension]. Bulletin Of the Institute of legislation of the Republic of Kazakhstan, 2 (47): P. 34-39. (In Russ.). 
8. Kirechyok E.V. 2016. Nacional'naya bezopasnost', nacional'nye interesy i strategicheskie nacional'nye prioritety Rossijskoj Federacii v kontekste obespecheniya prav cheloveka [National security, national interests and strategic national priorities of the Russian Federation in the context of ensuring human rights]. Penitentiary law: legal theory and law enforcement practice, 4 (10): 85-89. (In Russ.).

9. Kirilenko V.P., Alekseev G.V. 2018. Protivodejstvie ideologii sovremennogo terrorizma [Counteraction to the ideology of modern terrorism]. Management consulting, 5 (113): 8-18.

10. Kubyakin E.O., Gorbenko A.I. 2014. Protivodejstvie terroristicheskim ugrozam na federal'nom i municipal'nom urovnyah transformiruyushchegosya rossijskogo obshchestva: sociologicheskij analiz [Counteraction to terrorist threats at the Federal and municipal levels of the transforming Russian society: sociological analysis]. Bulletin of the Moscow state humanitarian and economic Institute, 3 (19): 16-19.

11. Kubyakin E.O., Plotnikov V.V. 2015. Sociologicheskoe issledovanie predposylok vozniknoveniya ekstremizma [Sociological study of the prerequisites for the emergence of extremism]. In: Extremism and its negative impact on the level of national security of Russia: criminological and economic aspects. Materials of the II all Russian scientific and practical conference. Krasnodar University of the Ministry of internal Affairs of Russia. 198 p. (In Russ.).

12. Kubyakin E.O., Plotnikov V.V. 2015. Fenomen social'nogo soznaniya kak intencional'nyj orientir issledovaniya problemy ekstremizma [The phenomenon of social consciousness as an intentional reference point for the study of the problem of extremism]. Society and law, 4 (54): 289-293. (In Russ.).

13. Kubyakin E.O., Plotnikov V.V. 2016. Protivodejstvie social'noj destruktivnosti v usloviyah global'noj transformacii obshchestva: upravlencheskij aspekt [Counteraction of social destructiveness in the conditions of global transformation of society: managerial aspect]. Man. Society. Inclusion, 2-1(26): 35-40.

14. Kubyakin E.O., Plotnikov V.V. 2016. Sociokul'turnaya determinirovannost' individual'noj deyatel'nosti. Analiz faktorov social'nyh protivorechij [Socio-cultural determinism of the individual activities. Analysis of factors of social contradictions]. Philosophy of law, 1 (74): 55-58. (In Russ.).

15. Kubyakin E.O., Karnaushenko L.V., Kulikov E.M., Gorodentsev G.A. 2015. Ekstremizm v usloviyah progressa informacionno-komp'yuternyh tekhnologij [Extremism in the conditions of progress of information and computer technologies]. Krasnodar University of the Ministry of internal Affairs of Russia. 102 p.

16. Lipinsky D.A. 2018. O spetsialiste $v$ sfere pravotvorchestva [About a specialist in the field of law-making]. Legal science and practice: Bulletin of the Nizhny Novgorod Academy of the Ministry of internal Affairs of Russia, 2 (42): 455-457. (In Russ.).

17. Smorgunova V.Y., Kalinin E.Y. 2019. Evolyutsiya idei pravosudiya v Rossii: ot poiska spravedlivosti k kare i obratno [Evolution of the idea of justice in Russia: from the search for justice to the penalty and back]. Legal science: history and modernity. Saint-Petersburg. Foundation for the promotion of science and education in the field of law enforcement "University", 1: 186-192. (In Russ.).

18. Tsybulevskaya O.I. 2014. Gosudarstvo i grazhdanskoe obshchestvo: metodologicheskii aspekt vzaimodeistviya [State and civil society: methodological aspect of interaction]. In: Responsibility of the government to civil society: mechanisms of control and interaction: proceedings of the conference. Saratov. Povolzhsky institute of management named after p. A. Stolypin. 272 p. (In Russ.).

19. Tsybulevskaya O.I., Milusheva T.V. 2007. Nravstvenno-pravovaya kul'tura sub"ektov vlasti i nekotorye voprosy pravoprimeneniya po usmotreniyu [Moral and legal culture of subjects of power and some issues of law enforcement at discretion]. Leningrad legal journal, 4 (10): 18-38. (In Russ.).

20. Tsybulevskaya O.I., Milusheva T.V. 2008. Obshchestvennyi kontrol' kak faktor ogranicheniya vlasti [Public control as a factor of power restriction]. Law and management. XXI century, 3 (8): 28-33.

\section{ИНФОРМАЦИЯ ОБ АВТОРЕ}

Миц Денис Сергеевич, к. юр. н., эксперт Парламентской Ассамблеи Организации Договора о коллективной безопасности (ОДКБ), г. Санкт-Петербург, Россия.

\section{INFORMATION ABOUT THE AUTHOR}

Denis S. Mits, candidate of law, expert of the parliamentary Assembly of the collective security Treaty Organization (CSTO), Saint Petersburg, Russia. 